\title{
Metabolic syndrome is associated with better prognosis in patients with tongue squamous cell carcinoma
}

Lan Zou ${ }^{1 \dagger}$, Tian-Run Liu ${ }^{2+}$ and An-Kui Yang ${ }^{1 *}$

\begin{abstract}
Introduction: Metabolic syndrome (MS) is associated with several cancers, but it is not clear whether MS affects the prognosis of tongue squamous cell carcinoma (TSCC). This study aimed to evaluate the prognostic value of MS in TSCC.

Methods: Clinical data from 252 patients with TSCC who were initially treated at the Sun Yat-sen University Cancer Center between April 1998 and June 2011 were collected, and the associations between MS and clinicopathologic factors were retrospectively analyzed. Prognostic outcomes were examined by Kaplan-Meier analysis and Cox regression analysis.

Results: Of the 252 patients, 48 were diagnosed with MS. MS was associated with early N category in TSCC $(P<0.001)$. The patients with MS showed longer survival than those without MS $(P=0.028)$. MS was an independent prognostic factor for patients with TSCC.

Conclusions: MS is associated with early N category in TSCC. It is an independent prognostic factor for better survival in patients with TSCC.
\end{abstract}

Keywords: Metabolic syndrome, Tongue squamous cell carcinoma, Prognosis

\section{Background}

Oral squamous cell carcinoma (OSCC) is a common malignant tumor worldwide. OSCC accounts for over $90 \%$ of all oral cancers [1], and the most common location for this disease is the tongue [2]. Tongue squamous cell carcinoma (TSCC) is especially prevalent in lowincome communities in North France, East Europe, South America, and Southeast Asia, and 90\% of patients with TSCC are over 45 years old [3]. TSCC seriously affects quality of life of the patients and carries a poor prognosis, with a 5-year overall survival (OS) rate of $56 \%[4]$.

Metabolic syndrome (MS) is a cluster of metabolic abnormalities. The pathophysiologic basis of MS is insulin

\footnotetext{
* Correspondence: yangak@sysucc.org.cn

${ }^{\dagger}$ Equal contributors

'Department of Head and Neck Surgery, Sun Yat-sen University Cancer

Center; State Key Laboratory of Oncology in South China; Collaborative Innovation Center for Cancer Medicine, Guangzhou, Guangdong 510060, P. R. China

Full list of author information is available at the end of the article
}

resistance [5]. The diagnosis criteria for MS include central obesity, hyperglycemia, hypertriglyceridemia, hypertension, and low serum concentration of high-density lipoprotein (HDL) [6]. MS is related to several cancers, including breast cancer, prostate cancer, and gastric cancer. MS and its components are associated with worse survival in breast cancer [7] and prostate cancer [8], but better survival for gastric cancer [9]. Obesity was reported to be an adverse independent prognostic factor for early-stage TSCC [10]. However, there is little information regarding the association between MS and TSCC or the impact of MS on TSCC patient survival. In this study, we tried to analyze whether the status of MS before treatment have any impact on the OS in patients with TSCC.

\section{Methods}

Patient selection

A total of 252 patients diagnosed with TSCC who were initially treated at the Sun Yat-sen University Cancer 
Center between April 1998 and June 2011 were involved in this study, including 145 males (58\%) and 107 females (42\%). Subject ages ranged from 20 to 89 years, with a median age of 52 years. None of these patients had distant metastasis before treatment. All patients underwent surgery; 59 (23\%) underwent multimodality therapy including surgery. Surgical margins were tumor-free for all patients. The data regarding MS and its components were recorded before treatment. The OS was defined as the duration from the date of initial treatment to the date of death or the last follow-up (July 2014). This study followed the Declaration of Helsinki for medical protocol and ethics. Study approval was obtained from independent ethics committees at Cancer Center of Sun Yat-Sen University.

\section{Diagnosis criteria of MS}

According to the National Cholesterol Education Program's Adult Treatment Panel III, our diagnosis criteria of MS included (1) fasting plasma glucose (GLU) $\geq 6.1 \mathrm{mmol} / \mathrm{L}$ or a diagnosis of diabetes; (2) abdominal obesity, with a body mass index (BMI) $\geq 25 \mathrm{~kg} / \mathrm{m}^{2}$; (3) triglycerides (TG) $\geq 1.7 \mathrm{mmol} / \mathrm{L}$; (4) high-density lipoprotein (HDL) $\leq 1.04 \mathrm{mmol} / \mathrm{L}$ for males and $\leq 1.3 \mathrm{mmol} / \mathrm{L}$ for females; and (5) hypertension, with the systolic blood pressure (BP) $\geq 130 / 80 \mathrm{mmHg}$. Meeting 3 or more of the criteria was necessary for diagnosis [9].

\section{Statistical analyses}

The chi-square test was performed to analyze the relationship between MS and clinicopathologic factors of TSCC. Kaplan-Meier and log-rank tests were used for survival analysis. Multivariate Cox regression analysis was performed for significant variables identified by using univariate analysis. SPSS 16.0 software was used for all analyses. A $P$ value of $<0.05$ was considered statistically significant.

\section{Results}

\section{Association between MS and clinicopathologic characteristics of TSCC}

The clinicopathologic characteristics of 252 patients are shown in Table 1. Of these patients, 48 (19.1\%) were diagnosed with MS. MS was associated with early $\mathrm{N}$ category $(P<0.001)$. However, there was no association between MS and age, gender, T stage, pathologic grade, treatment strategy, or tumor location.

\section{Relationship between MS and survival of TSCC patients}

At the time of the last follow-up, 184 patients $(73.0 \%)$ were alive, and $68(27.0 \%)$ died of cancer-related diseases. Figure 1 demonstrates that the patients with MS had better OS than those without MS $(P=0.028)$. The Cox proportional hazards model was used to verify
Table 1 Association between MS and clinicopathologic characteristics of patients with TSCC

\begin{tabular}{|c|c|c|c|c|}
\hline \multirow[t]{2}{*}{ Characteristic } & \multicolumn{3}{|c|}{ Number of patients (\%) } & \multirow[t]{2}{*}{$P$ value } \\
\hline & Total & $\begin{array}{l}\text { With } \\
\text { MS }\end{array}$ & $\begin{array}{l}\text { Without } \\
\text { MS }\end{array}$ & \\
\hline Age (years) & & & & 0.426 \\
\hline$\geq 52$ & $134(53)$ & $28(58)$ & $106(52)$ & \\
\hline$<52$ & $118(47)$ & $20(42)$ & $98(48)$ & \\
\hline Sex & & & & 0.273 \\
\hline Male & $145(58)$ & $31(65)$ & $114(56)$ & \\
\hline Female & $107(42)$ & $17(35)$ & $90(44)$ & \\
\hline T category & & & & 0.524 \\
\hline $\mathrm{T} 1 / \mathrm{T} 2$ & $222(88)$ & $41(85)$ & $181(89)$ & \\
\hline $\mathrm{T} 3 / \mathrm{T} 4$ & $30(12)$ & $7(15)$ & $23(11)$ & \\
\hline $\mathrm{N}$ category & & & & $<0.001$ \\
\hline No & $130(52)$ & $36(75)$ & $94(46)$ & \\
\hline $\mathrm{N}+$ & $122(48)$ & $12(25)$ & $110(54)$ & \\
\hline Pathologic grade & & & & 0.598 \\
\hline Well differentiated & $184(73)$ & $33(69)$ & $151(74)$ & \\
\hline Moderately differentiated & $58(23)$ & $12(25)$ & $46(23)$ & \\
\hline Poorly differentiated & $10(4)$ & $3(6)$ & $7(3)$ & \\
\hline Treatment & & & & 0.639 \\
\hline Surgery alone & $193(77)$ & $38(79)$ & $155(76)$ & \\
\hline Multimodality therapy & $59(23)$ & $10(21)$ & $49(24)$ & \\
\hline Tumor location & & & & 0.653 \\
\hline $\begin{array}{l}\text { Lateral margin of the } \\
\text { tongue }\end{array}$ & $185(73)$ & $34(71)$ & $151(74)$ & \\
\hline Other locations ${ }^{a}$ & $67(27)$ & $14(29)$ & $53(26)$ & \\
\hline Total & 252 & 48 & 204 & \\
\hline
\end{tabular}

MS, metabolic syndrome; TSCC, tongue squamous cell carcinoma. ${ }^{\mathrm{a}}$ Other locations here include the apex linguae, dorsum, and ventrum of the tongue.

whether MS and other variables were independent prognostic factors for TSCC patients. The univariate analysis results showed that MS, sex, age, T category, N category, pathologic grade, and treatment strategy were associated with OS. Multivariate Cox regression analysis revealed that MS, age, $\mathrm{T}$ category, $\mathrm{N}$ category, pathologic grade, and treatment strategy were independent prognostic factors for patients with TSCC (Table 2).

\section{Discussion}

Our study demonstrated that MS was associated with early N category in TSCC. In addition, MS was an independent prognostic factor for better survival in patients with TSCC.

This study first reported the association of MS with early N category in TSCC. Previous reports demonstrated that MS was associated with better differentiation in gastric cancer cells [9], whereas others indicated that MS or its components were associated with a more 


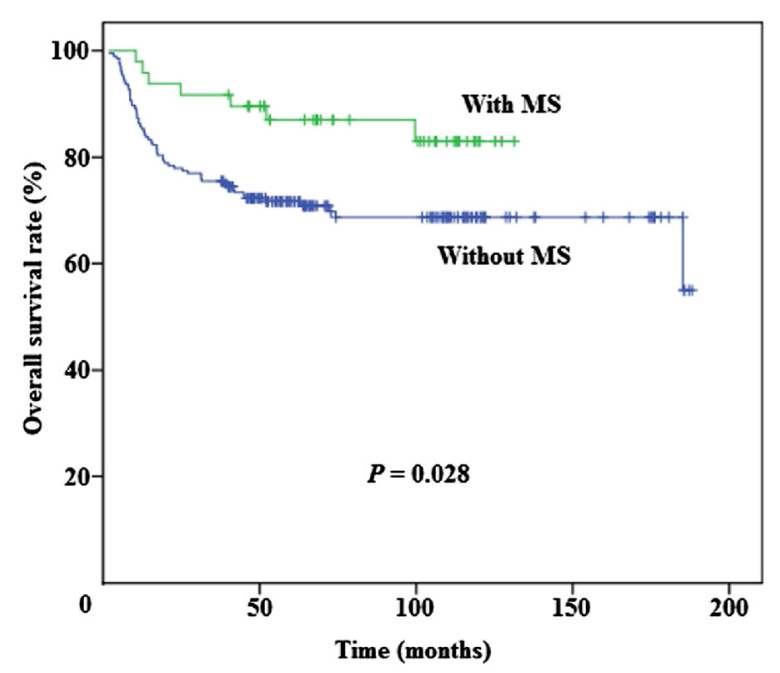

Figure 1 Overall survival curves for patients with tongue squamous cell carcinoma (TSCC) according to the status of metabolic syndrome (MS). Kaplan-Meier analysis results indicate that patients with MS have better overall survival than those without MS $(P=0.028)$.

aggressive tumor type in colon cancer and prostate cancer [11,12]; the influence of MS on breast cancer remains controversial $[13,14]$. The mechanism by which MS influences $\mathrm{N}$ category is not well understood. Insulin receptor and insulin-like growth factor 1 (IGF-1) are expressed in most cancer cells, and IGF-1 can stimulate invasion and proliferation of cervical cancer cells [15]. The patients with diabetes had low concentrations of IGF-1 [16]. Moreover, the insulin receptor-activating signaling pathways may offer protection from invasion and metastasis of cancer cells $[17,18]$; however, the mechanism remains unclear and requires further investigation. In addition, underweight patients in China were associated with lower income and education, and they were less likely to receive the correct treatment when diagnosed with an early-stage disease. The TNM classification significantly affects tongue cancer prognosis; the earlier the classification, the better the prognosis. In our study, $\mathrm{T}$ category and $\mathrm{N}$ category were independent prognostic factors for patients with TSCC. Liu et al. [19] reported that the 5-year OS rates for patients with stages I, II, III, and IV oral cancers were $79.8 \%, 68.2 \%, 57.2 \%$, and $50.4 \%$, respectively. Thus, it is critical to diagnose tongue cancer in early stages [3]. In addition, the pathologic grade significantly affects prognosis of the patients. The patients who underwent multimodality therapy in our study usually had late-stage disease, which leaded to worse prognosis of these patients.

The impact of MS on cancer patient prognosis, including cervical cancer, remains controversial. For example, MS predicts poor survival in patients with prostate cancer and breast cancer $[7,8]$, whereas Wei et al. [9] reported that old patients with early-stage gastric cancer and MS had a better prognosis. In patients with earlystage colon cancer, diabetes and hypertension predicted poor survival, but dyslipidemia predicted good survival $[20,21]$. Another study reported increased odds of MS among American women with a history of cervical cancer, but no association was observed between the single component of MS and cervical cancer [22]. Several reports suggested that leanness might be associated with poor outcome for patients with cervical cancer [19,23-26]. However, obesity was considered an independent predictor of increased risk of death in patients with earlystage tongue cancer [10]. However, patients in these studies had various tumor sites and different pathologic diagnoses. In addition, some of these studies were limited by small sample sizes. Our study found that MS was associated with better prognosis in patients with TSCC. Malnutrition is common in patients with head and neck cancer, especially in oral tongue cancer, which seriously affects the patient's nutritional status, so weight loss before treatment was associated with poor prognosis. In addition, patients without MS are more likely to suffer from nutritional deficiency, which may lead to poor prognosis. Good nutritional status could improve survival by strengthening immunity and providing high tolerance for lengthy therapeutic periods. A retrospective research of oral cavity cancer and oropharyngeal cancer showed that weight loss was a strong predictor of death $[19,24,26]$. Another study also reported poor survival in oral cancer patients with a BMI $<22.8 \mathrm{~kg} / \mathrm{m}^{2}$ before surgery [19].

Several individual components of MS have been recognized as carcinogenic. However, our research did not identify any significant influence of MS components on TSCC prognosis. This result was similar to those of previous studies $[9,22]$. Epidemiologic studies indicated that clustering MS components increased the carcinogenic effect on colorectal cancer development and mortality compared with individual factors $[27,28]$. Our findings align with this theory of synergism among MS components, as none of the individual MS components was associated with TSCC, but when clustering at least 3 components, this association became significant and remained significant when adjusting for other risk factors for TSCC. Further investigations are needed to better understand the effects of MS and its components on survival in TSCC patients.

The molecular and cellular mechanisms by which MS affects cancer patient survival are very complicated. Smith et al. [29] reported that IGF-1 is a potential pathway linking the environment with cancer. High levels of IGF-1 increases the risk of cancer and aggressiveness of malignancies. Cowey et al. [30] reported that TG 
Table 2 Univariate and multivariate Cox regression analyses for overall survival in patients with TSCC

\begin{tabular}{|c|c|c|c|c|}
\hline \multirow[t]{2}{*}{ Variable } & \multicolumn{2}{|l|}{ Univariate analysis } & \multicolumn{2}{|c|}{ Multivariate analysis } \\
\hline & $\mathrm{HR}(95 \% \mathrm{Cl})$ & $P$ value & $\mathrm{HR}(95 \% \mathrm{Cl})$ & $P$ value \\
\hline$\overline{S e x^{a}}$ & $0.591(0.356-0.984)$ & 0.043 & $0.681(0.398-1.166)$ & 0.162 \\
\hline \multicolumn{5}{|l|}{ Age (years) } \\
\hline$<52$ & Ref & & Ref & \\
\hline$\geq 52$ & $1.823(1.100-3.020)$ & 0.020 & $2.149(1.279-3.614)$ & 0.004 \\
\hline Tumor location ${ }^{b}$ & $1.032(0.607-1.754)$ & 0.908 & & \\
\hline \multicolumn{5}{|l|}{ Pathologic grade } \\
\hline Well differentiated & Ref & & Ref & \\
\hline Moderately differentiated & $2.483(1.475-4.183)$ & 0.001 & $2.417(1.417-4.124)$ & 0.001 \\
\hline Poorly differentiated & $4.728(2.101-10.639)$ & $<0.001$ & $2.726(1.172-6.336)$ & 0.020 \\
\hline \multicolumn{5}{|l|}{$T$ category } \\
\hline $\mathrm{T} 1 / \mathrm{T} 2$ & Ref & & Ref & \\
\hline $\mathrm{T} 3 / \mathrm{T} 4$ & $3.575(2.054-6.223)$ & $<0.001$ & $2.007(1.091-3.691)$ & 0.025 \\
\hline \multicolumn{5}{|l|}{ N category } \\
\hline NO & Ref & & Ref & \\
\hline $\mathrm{N}+$ & $4.846(2.725-8.618)$ & $<0.001$ & $3.408(1.873-6.202)$ & $<0.001$ \\
\hline Treatment $^{c}$ & $3.963(2.451-6.407)$ & $<0.001$ & $2.559(1.492-4.392)$ & 0.001 \\
\hline \multicolumn{5}{|l|}{ MS } \\
\hline With MS & Ref & & Ref & \\
\hline Without MS & $2.342(1.070-5.125)$ & 0.033 & $2.518(1.126-5.631)$ & 0.024 \\
\hline \multicolumn{5}{|c|}{ One component meets the criteria of MS } \\
\hline BMI & $0.692(0.330-1.448)$ & 0.328 & & \\
\hline GLU & $0.938(0.491-1.792)$ & 0.846 & & \\
\hline $\mathrm{BP}$ & $0.745(0.455-1.221)$ & 0.243 & & \\
\hline TG & $0.695(0.391-1.235)$ & 0.215 & & \\
\hline $\mathrm{HDL}$ & $0.818(0.491-1.361)$ & 0.439 & & \\
\hline
\end{tabular}

${ }^{a}$ Male versus female; ${ }^{b}$ the margo lateralis linguae versus other locations (the apex linguae, dorsum, and ventrum of the tongue); ${ }^{c}$ surgery alone versus multimodality therapy. TSCC, tongue squamous cell carcinoma; HR, hazard ratio; $\mathrm{Cl}$, confidence interval; Ref, reference; MS, metabolic syndrome; BMI, body mass index; GLU, fasting plasma glucose; BP, blood pressure; TG, triglycerides; HDL, high-density lipoprotein.

promoted cancer cell proliferation and showed antiapoptotic activity due to the generation of reactive oxygen species (ROS) and oxidative stress, which cause DNA damage. Obesity is linked with higher incidence and mortality of several cancers, but there are still some opposing opinions $[10,19,23,24,26]$. Levels of adipokine, leptin, and adiponectin in obesity can affect several signal transduction pathways involved in cell survival [31], and Shin et al. [32] reported that the adiponectin receptor is related to gastric cancer development, progression, and poor survival. BMI influences cancers by releasing several inflammatory mediators, such as tumor necrosis factor alpha, interleukin-6, and prostaglandin E2 [33]. A previous study reported an association between cervical cancer and low HDL levels [22].

Our study had some limitations. First, it was a retrospective study. Second, this study did not include diseasefree survival due to limited clinical data. Third, we did not know the exact time of the occurrence of MS, which may lead to an overestimation of the associations.

\section{Conclusions}

In conclusion, this study first demonstrated that MS is associated with early $\mathrm{N}$ category and predicts good prognosis in patients with TSCC. Understanding the underlie molecular and cellular mechanisms may provide clues to prevent cancer development. Similarly, therapeutic interventions targeting these molecular mechanisms might manifest a positive perspective for the treatment of TSCC. In addition, our results indicate that good nutritional status may improve survival in patients with TSCC.

\section{Consent}

Written informed consent was obtained from the patient for the publication of this report and any accompanying images. 


\section{Competing interests}

The authors declare that they have no competing interests.

\section{Authors' contributions}

$L Z$ developed the algorithm. A-KY, T-RL, and LZ carried out most of the analyses. A-KY, T-RL, and $L Z$ participated in the design of the study and helped algorithm development. T-RL and $L Z$ drafted the manuscript. A-KY conceived and coordinated the study. All authors have read and approved the final manuscript.

\section{Author details}

${ }^{1}$ Department of Head and Neck Surgery, Sun Yat-sen University Cancer Center; State Key Laboratory of Oncology in South China; Collaborative Innovation Center for Cancer Medicine, Guangzhou, Guangdong 510060, P. R. China. ${ }^{2}$ Department of Otorhinolaryngology Head and Neck Surgery, The Sixth Affiliated Hospital of Sun Yat-sen University, Guangzhou, Guangdong 510655, P. R. China.

\section{Received: 22 August 2014 Accepted: 2 December 2014}

\section{Published online: 08 April 2015}

\section{References}

1. Chen YK, Huang HC, Lin LM, Lin CC. Primary oral squamous cell carcinoma: an analysis of 703 cases in southern Taiwan. Oral Oncol. 1999;35:173-9.

2. Hirata RM, Jaques DA, Chambers RG, Tuttle JR, Mahoney WD. Carcinoma of the oral cavity. An analysis of 478 cases. Ann Surg. 1975;182:98-103.

3. Scully C, Bagan J. Oral squamous cell carcinoma overview. Oral Oncol. 2009;45:301-8

4. Bell RB, Kademani $D$, Homer $L$, Dierks EJ, Potter BE. Tongue cancer: is there a difference in survival compared with other subsites in the oral cavity? Oral Maxillofac Surg. 2007;65:229-36.

5. Ayturk S, Gursoy A, Kut A, Anil C, Nar A, Tutuncu NB. Metabolic syndrome and its components are associated with increased thyroid volume and nodule prevalence in a mild-to-moderate iodine-deficient area. Eur Endocrinol. 2009;161:599-605.

6. Alberti KG, Eckel RH, Grundy SM, Zimmet PZ, Cleeman Jl, Donato KA, et al. Harmonizing the metabolic syndrome: a joint interim statement of the International Diabetes Federation Task Force on Epidemiology and Prevention; National Heart, Lung, and Blood Institute; American Heart Association; World Heart Federation; International Atherosclerosis Society; and International Association for the Study of Obesity. Circulation. 2009;120:1640-5

7. Reeves KW, McLaughlin V, Fredman L, Ensrud K, Cauley JA. Components of metabolic syndrome and risk of breast cancer by prognostic features in the study of osteoporotic fractures cohort. Cancer Causes Control. 2012;23:1241-51.

8. Ozbek E, Otunctemur A, Dursun M, Sahin S, Besiroglu H, Koklu I, et al. The metabolic syndrome is associated with more aggressive prostate cancer. Asian Pac J Cancer Prev. 2014;15:4029-32.

9. Wei XL, Qiu MZ, Lin HX, Zhang Y, Liu JX, Yu HM, et al. Patients with old age or proximal tumors benefit from metabolic syndrome in early stage gastric cancer. PLoS One. 2014;9:e89965.

10. lyengar NM, Kochhar A, Morris PG, Morris LG, Zhou XK, Ghossein RA, et al. Impact of obesity on the survival of patients with early-stage squamous cell carcinoma of the oral tongue. Cancer. 2014;120:983-91.

11. Xiang $Y Z$, Xiong $H$, Cui ZL, Jiang SB, Xia QH, Zhao Y, et al. The association between metabolic syndrome and the risk of prostate cancer, high-grade prostate cancer, advanced prostate cancer, prostate cancer-specific mortality and biochemical recurrence. J Exp Clin Cancer Res. 2013;32:9.

12. Healy LA, Howard JM, Ryan AM, Beddy P, Mehigan B, Stephens R, et al. Metabolic syndrome and leptin are associated with adverse pathological features in male colorectal cancer patients. Colorectal Dis. 2012;14:157-65.

13. Colonna SV, Douglas Case L, Lawrence JA. A retrospective review of the metabolic syndrome in women diagnosed with breast cancer and correlation with estrogen receptor. Breast Cancer Res Treat. 2012;131:325-31.

14. Healy LA, Ryan AM, Carroll P, Ennis D, Crowley V, Boyle T, et al. Metabolic syndrome, central obesity and insulin resistance are associated with adverse pathological features in postmenopausal breast cancer. Clin Oncol (R Coll Radiol). 2010;22:281-8.
15. Shen MR, Hsu YM, Hsu KF, Chen YF, Tang MJ, Chou CY. Insulin-like growth factor 1 is a potent stimulator of cervical cancer cell invasiveness and proliferation that is modulated by alphavbeta3 integrin signaling. Carcinogenesis. 2006;27:962-71.

16. van Dijk PR, Logtenberg SJ, Groenier KH, Kleefstra N, Bilo HJ, Arnqvist HJ. Effect of i.p. insulin administration on IGF1 and IGFBP1 in type 1 diabetes. Endocr Connect. 2014;3:17-23.

17. Zhang H, Pelzer AM, Kiang DT, Yee D. Down-regulation of type I insulin-like growth factor receptor increases sensitivity of breast cancer cells to insulin. Cancer Res. 2007;67:391-7.

18. Mardilovich K, Pankratz SL, Shaw LM. Expression and function of the insulin receptor substrate proteins in cancer. Cell Commun Signal. 2009;7:14.

19. Liu SA, Tsai WC, Wong YK, Lin JC, Poon CK, Chao SY, et al. Nutritional factors and survival of patients with oral cancer. Head Neck. 2006;28:998-1007.

20. Yang Y, Mauldin PD, Ebeling M, Hulsey TC, Liu B, Thomas MB, et al. Effect of metabolic syndrome and its components on recurrence and survival in colon cancer patients. Cancer. 2013;119:1512-20.

21. Shen $Z$, Ye Y, Bin L, Yin M, Yang $X$, Jiang $K$, et al. Metabolic syndrome is an important factor for the evolution of prognosis of colorectal cancer: survival, recurrence, and liver metastasis. Am J Surg. 2010;200:59-63.

22. Penaranda EK, Shokar N, Ortiz M. Relationship between metabolic syndrome and history of cervical cancer among a US national population. ISRN Oncol. 2013;2013:840964

23. Gaudet MM, Olshan AF, Chuang SC, Berthiller J, Zhang ZF, Lissowska J, et al. Body mass index and risk of head and neck cancer in a pooled analysis of case-control studies in the International Head and Neck Cancer Epidemiology (INHANCE) Consortium. Int J Epidemiol. 2010;39:1091-102.

24. Franceschi S, Dal Maso L, Levi F, Conti E, Talamini R, La Vecchia C. Leanness as early marker of cancer of the oral cavity and pharynx. Ann Oncol. 2001;12:331-6.

25. Van Bokhorst-de Van der Schuer MA, Langendoen SI, Vondeling H, Kuik DJ, Quak JJ, Van Leeuwen PA. Perioperative enteral nutrition and quality of life of severely malnourished head and neck cancer patients: a randomized clinical trial. Clin Nutr. 2000;19:437-44

26. Nguyen TV, Yueh B. Weight loss predicts mortality after recurrent oral cavity and oropharyngeal carcinomas. Cancer. 2002;95:553-62.

27. Colangelo LA, Gapstur SM, Gann PH, Dyer AR, Liu K. Colorectal cancer mortality and factors related to the insulin resistance syndrome. Cancer Epidemiol Biomarkers Prev. 2002;11:385-91.

28. Trevisan M, Liu J, Muti P, Misciagna G, Menotti A, Fucci F, et al. Markers of insulin resistance and colorectal cancer mortality. Cancer Epidemiol Biomarkers Prev. 2001:10:937-41.

29. Smith GD, Gunnell D, Holly J. Cancer and insulin-like growth factor-I. A potential mechanism linking the environment with cancer risk. BMJ. 2000;321:847-8.

30. Cowey S, Hardy RW. The metabolic syndrome: a high-risk state for cancer? Am J Pathol. 2006;169:1505-22.

31. van Kruijsdijk RC, van der Wall E, Visseren FL. Obesity and cancer: the role of dysfunctional adipose tissue. Cancer Epidemiol Biomarkers Prev. 2009;18:2569-78.

32. Shin E, do Park J, Kim HH, Won NH, Choe G, Lee HS. Adiponectin receptor expression in gastric carcinoma: implications in tumor development and progression. J Cancer Res Clin. 2013;139:709-18.

33. Olefsky JM, Glass CK. Macrophages, inflammation, and insulin resistance. Annu Rev Physiol. 2010:72:219-46. 